\title{
Cerebrovascular Disease in COVID-19
}

\author{
(1) Michael F. Goldberg, ${ }^{(}$Morton F. Goldberg, ${ }^{-}$R. Cerejo, and ${ }^{-1}$ A.H. Tayal
}

\section{ABSTRACT}

SUMMARY: Coronavirus disease 19 (COVID-19) is a pandemic originating in Wuhan, China, in December 2019. Early reports suggest that there are neurologic manifestations of COVID-19, including acute cerebrovascular disease. We report a case of COVID-19 with acute ischemic stroke. To our knowledge, this is the first reported case of COVID-19-related cerebral infarcts that includes brain imaging at multiple time points and CT angiography. There is a growing body of published evidence that complications of COVID19 are not limited to the pulmonary system. Neuroradiologists should be aware of a wide range of neurologic manifestations, including cerebrovascular disease.

ABBREVIATIONS: ACA = anterior cerebral artery; ACE2 = angiotensin converting enzyme 2; COVID-19 = coronavirus disease 19; SARS-CoV-2 = Severe Acute Respiratory Syndrome coronavirus-2

C oronavirus disease 2019 (COVID-19), the pandemic disease caused by the Severe Acute Respiratory Syndrome coronavirus-2 (SARS-CoV-2), began in December 2019, in Wuhan, China. ${ }^{1}$ Common presenting symptoms and signs of COVID-19 include fever, cough, and shortness of breath. ${ }^{2}$ In addition, there have been typical pulmonary findings that have been described on chest CT and chest radiographs. ${ }^{3}$

There is a growing body of published evidence that complications of COVID-19 are not limited to the pulmonary system. ${ }^{4}$ They include a wide range of neurologic manifestations, such as acute cerebral infarcts. ${ }^{5,6}$ We report a case of acute COVID-19 with acute cerebral infarcts, demonstrated by NCCT and extracranial/intracranial CTA. To our knowledge, this is the first reported case of COVID-19-related cerebral infarcts to include brain imaging at multiple time points and CT angiographic imaging.

\section{CASE REPORT}

A 64-year-old man presented to the emergency department of Allegheny General Hospital with a wake-up stroke with symptoms of left-sided hemiparesis and shortness of breath. The patient's last

Received April 17, 2020; accepted after revision April 21.

From the Imaging Institute, Division of Neuroradiology (Michael F.G.), and Neuroscience Institute, Cerebrovascular Center (R.C., A.H.T.), Allegheny Health Network, Pittsburgh, Pennsylvania; and Department of Ophthalmology (Morton F.G.), Johns Hopkins Medical Institutions, Baltimore, Maryland.

Please address correspondence to Michael F. Goldberg, MD, MPH, Director, Division of Neuroradiology, Imaging Institute, Allegheny General Hospital, 320 E North Ave, Pittsburgh, PA 15212; e-mail: Michael.goldberg@ahn.org

- Indicates open access to non-subscribers at www.ajnr.org

http://dx.doi.org/10.3174/ajnr.A6588 known well time was $>4.5$ hours from onset, and intravenous thrombolysis was not recommended. Sixteen days before admission, the patient had been evaluated for fever and myalgias and diagnosed with COVID-19 after testing positive for SARS-CoV-2. The diagnosis of COVID-19 was confirmed during the hospital admission via nasopharyngeal swab and reverse transcription polymerase chain reaction testing. The patient's relevant medical history included hypertension, aplastic anemia, and splenectomy.

In the emergency department, the patient was tachycardic and hypertensive; demonstrated rapid progressive acute hypoxemic respiratory failure; and required intubation with mechanical ventilation. A chest CT revealed extensive, bilateral ground-glass opacities, consistent with acute respiratory distress syndrome due to COVID19. Due to respiratory and hemodynamic instability, immediate brain and CT angiographic imaging in the emergency department could not be performed safely.

Approximately 5 hours after hospital admission, NCCT revealed large areas of mild hypoattenuation and loss of gray-white differentiation in the territories of the right MCA and bilateral anterior cerebral arteries (ACAs) (Fig 1). Extracranial/intracranial CTA revealed a $20-\mathrm{mm}$ segmental high-grade stenosis of the proximal ICA at the level of the ICA bifurcation (Fig 2). Given that the patient had evidence of mild, diffuse extracranial and intracranial atherosclerotic disease, the high-grade stenosis of the right ICA was favored to represent atherosclerotic disease; however, acute thrombus could have had a similar appearance. The intracranial CTA revealed no large-vessel occlusion, but there was markedly diminished flow in the distal branches of the right MCA and the bilateral ACAs (Fig 2). Approximately 24 hours later, a repeat NCCT 

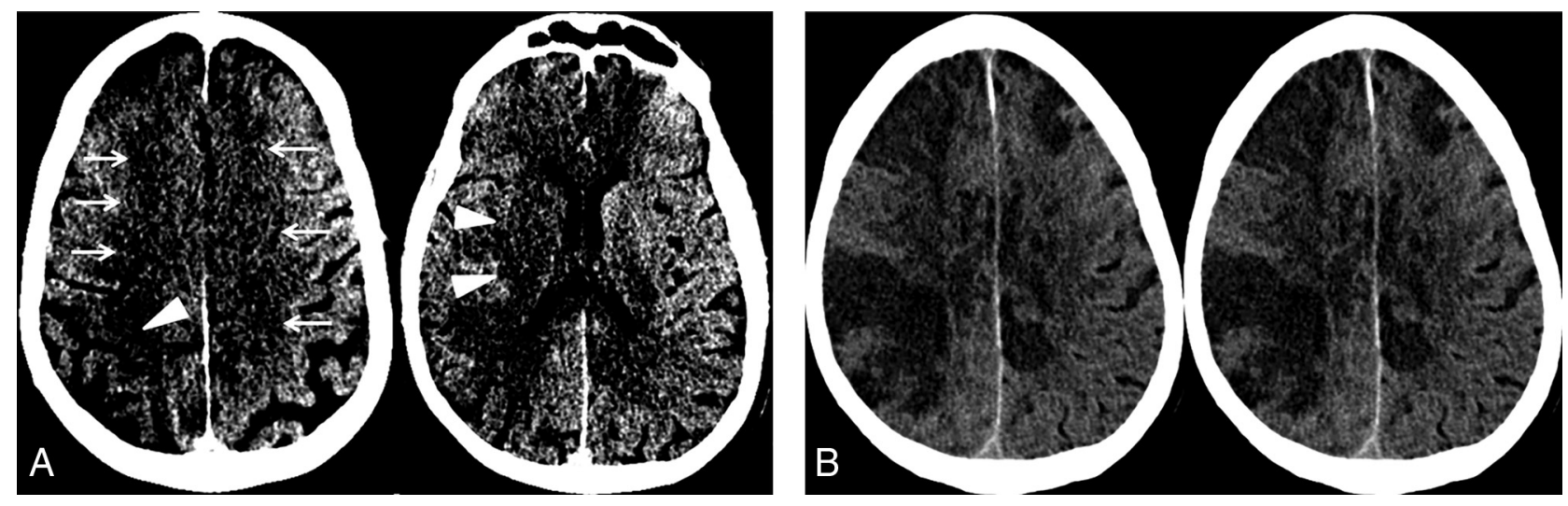

FIG 1. A, NCCT on the day of admission demonstrates subtle findings of acute ischemia in the right MCA (arrowheads) and bilateral ACA (arrows) territories, including hypoattenuation and loss of gray-white differentiation. B, Repeat NCCT on hospital day 2 demonstrates progression of acute infarcts in the right MCA and bilateral ACA territories, including worsening edema and mass effect.
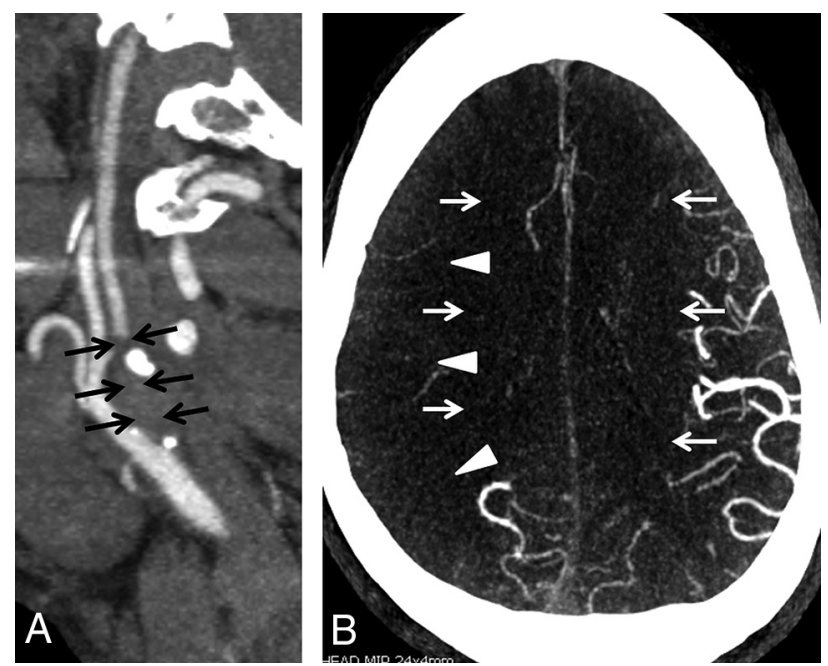

FIG 2. A, Sagittal MIP image from the extracranial CTA performed on the day of admission demonstrates a segmental high-grade stenosis of the proximal right internal carotid artery (arrows). There is normal flow in the right common carotid and external carotid arteries. B, Axial MIP of the intracranial CTA performed on the day of admission demonstrates markedly decreased vascular flow within the branches of the right MCA (arrowheads) and bilateral ACAs (arrows). Conversely, there is normal vascular flow in the left MCA and bilateral posterior cerebral artery territories.

revealed worsening cerebral edema and mass effect of the infarcts of the right MCA and bilateral ACA territories, consistent with the expected evolution of acute ischemia (Fig 1).

Laboratory testing showed an elevated white blood cell count and evidence of coagulopathy, including an elevated prothrombin time, increased D-dimer level, increased fibrinogen level, a markedly elevated serum ferritin level, and abnormal elevation of the antiphospholipid antibody, anticardiolipin immunoglobulin M.

\section{DISCUSSION}

A recent case series of 214 patients with COVID-19 from Wuhan, China, reported that $36 \%$ of patients demonstrated neurologic manifestations, and acute cerebrovascular disease was reported in $6 \%$ of severely affected patients. ${ }^{5}$ The precise mechanism for the cerebral ischemia in the clinical setting of COVID-19 is not known, but there is strong evidence for the development of a transient hypercoagulable state, especially in severe disease. ${ }^{7}$

In a study of 191 patients with COVID-19 in Wuhan, China, researchers found that $\mathrm{D}$-dimer levels of $>1 \mu \mathrm{g} / \mathrm{L}$ were associated with an 18-fold increase in odds of death before discharge. ${ }^{2}$ $\mathrm{D}$-dimer is a product of fibrin clot degradation and is indicative of recent or current clot formation.

In Zhou et al, ${ }^{2}$ patients with COVID-19 with an elevated serum ferritin level of $>300 \mu \mathrm{g} / \mathrm{L}$ had a 9-fold increase in the odds of death before discharge. Hyperferritinemia, although nonspecific, can be a marker of an inflammatory response. ${ }^{8}$ Hyperferritinemia can also be seen in the antiphospholipid syndrome and its variant, catastrophic antiphospholipid syndrome, both of which are associated with arterial and venous thromboses. ${ }^{9}$ This patient with hyperferritinemia also had elevated anticardiolipin immunoglobulin $\mathrm{M}$ antibodies, and antiphospholipid syndrome has been recently implicated in the coagulopathy associated with cerebral ischemia in patients with COVID-19. ${ }^{10}$

Endothelial damage may also play a role in the pathogenesis of cerebral ischemia in severe COVID-19. Specifically, SARS$\mathrm{CoV}-2$ infects cells via binding of the spike protein of the virus to the angiotensin converting enzyme 2 (ACE2) receptors. ${ }^{11}$ ACE2 receptors are found not only in the alveolar epithelial cells of the lungs but also in the vascular endothelium. ${ }^{12}$ Therefore, patients with severe COVID-19 may be at risk of thrombogenesis and cerebral ischemia due to both biochemical hypercoagulable states and direct vascular endothelial injury. In our patient, this risk is a distinct possibility because there were large territorial infarcts despite the absence of an intracranial large-vessel occlusion.

In addition, myocardial injury has been reported in $22 \%$ of patients with COVID-19 requiring an intensive care unit, and cardiac embolization may also have a contributory role in COVID19-related cerebral ischemia. ${ }^{13}$

Finally, this patient had evidence of atherosclerotic disease. Systemic infection, such as that demonstrated in this patient, is associated with activation of immune and inflammatory pathways leading to plaque disruption, serving as a source of thrombosis. ${ }^{14}$

This patient died on hospital day 3 due to COVID-19, and clinical and laboratory evaluations were incomplete; therefore, a 
more precise pathogenic mechanism of the cerebral infarcts in this patient is indeterminate. It is also not known why only a small percentage of severely affected patients with COVID-19 have cerebral ischemia, whereas most do not.

In conclusion, we report a case of COVID-19 with acute cerebrovascular disease. We believe this is the first published case to include angiographic imaging. Manifestations of COVID-19 are not limited to the respiratory system, and neuroradiologists should be aware of the associated cerebrovascular disease and its potential underlying etiologies.

\section{ACKNOWLEDGMENT}

Jeremy Virag. Administrative support in the preparation of this manuscript.

Disclosures: Morton F. Goldberg-UNRELATED: Board Membership: Board of Directors, EyeGate Pharmaceuticals, Comments: no relevance to submitted manuscript; Employment: Johns Hopkins Medical School; Stock/Stock Options: board membership, EyeGate Pharmaceuticals. Russell Cerejo-UNRELATED: Consultancy: Medical Advisory Board, iSchemaView.

\section{REFERENCES}

1. Phelan AL, Katz R, Gostin LO. The novel coronavirus originating in Wuhan, China: challenges for global health governance. JAMA 2020 Jan 30. [Epub ahead of print] CrossRef Medline

2. Zhou F, Yu T, Du R, et al. Clinical course and risk factors for mortality of adult inpatients with Covid-19 in Wuhan, China: a retrospective cohort study. Lancet 2020;395:1054-62 CrossRef Medline

3. Kanne JP, Little BP, Chung JH, et al. Essentials for radiologists on COVID-19: an update-radiology scientific expert panel. Radiology 2020 Feb 27. [Epub ahead of print] CrossRef Medline
4. World Health Organization. Report of the WHO-China joint mission on coronavirus disease 2019 (COVID-19). February 16-24, 2020. https://www.who.int/docs/default-source/coronaviruse/who-chinajoint-mission-on-covid-19-final-report.pdf. Accessed April 15, 2020

5. Mao L, Jin H, Wang M, et al. Neurologic manifestations of hospitalized patients with coronavirus disease 2019 in Wuhan, China. JAMA Neurol 2020 Apr 10. [Epub ahead of print] CrossRef Medline

6. Helms J, Kremer S, Merdji H, et al. Correspondence: neurologic features in severe SARS-CoV-2 infection. N Engl J Med 2020 Apr 15. [Epub ahead of print] CrossRef Medline

7. Thachil J, Tang N, Gando S, et al. ISTH interim guidance on recognition and management of coagulopathy in COVID-19. J Thromb Haemost 2020;18:1023-26 CrossRef Medline

8. Rosário C, Zandman-Goddard G, Meyron-Holtz EG, et al. The hyperferritinemic syndrome: macrophage activation syndrome, Still's disease, septic shock and catastrophic antiphospholipid syndrome. BMC Med 2013;11:185 CrossRef Medline

9. Nayer A, Ortega L. Catastrophic antiphospholipid syndrome: a clinical review. J Nephropathol 2014;3:9-17 CrossRef Medline

10. Zhang Y, Xiao M, Zhang S. Coagulopathy and antiphospholipid antibodies in patients with Covid-19. N Engl J Med 2020;382:e38 CrossRef Medline

11. Hoffmann M, Kleine-Weber H, Schroeder S, et al. SARS-CoV-2 entry depends on ACE2 and TMPRSS2 and is blocked by a clinically proven protease inhibitor. Cell 2020;181:271-80.e8 CrossRef Medline

12. Clerkin KJ, Fried JA, Raikhelkar J, et al. Coronavirus disease 2019 (Covid-19) and cardiovascular disease. Circulation 2020 Mar 21. [Epub ahead of print] CrossRef Medline

13. Wang D, Hu B, Hu C, et al. Clinical characteristics of 138 hospitalized patients with 2019 novel coronavirus-infected pneumonia in Wuhan, China. JAMA 2020 Feb 7. [Epub ahead of print] CrossRef Medline

14. Libby P, Loscalzo J, Ridker P, et al. Inflammation, immunity, and infection in atherothrombosis: JACC review topic of the week. J Am Coll Cardiol 2018;72:2071-81 CrossRef Medline 